\title{
La percepción de las desigualdades: interacciones sociales y procesos sociohistóricos. El caso de Chile
}

\author{
KATHYA ARAUJO
}

Con la investigación empírica como apoyo, en este artículo nos acercamos a las razones por las cuales las desigualdades en la interacción en Chile se han constituido en un lente privilegiado para leer los acontecimientos sociales y establecer juicios respecto a la sociedad. La tesis que se defiende es que la relevancia de estas desigualdades revela la manera en que los procesos de transformación que han atravesado esta sociedad en las últimas décadas han cuestionado los principios ordenadores del lazo social al poner en entredicho lógicas sociales que, en especial en la sociabilidad, a lo largo de la historia mantuvieron intacta una concepción jerárquica y vertical de las relaciones sociales. Como argumento, se toma el caso de las interacciones en las calles.

PALABRAS CLAVE: desigualdades, interacciones sociales, lazo social, procesos sociohistóricos, Chile

The Perception of Inequalities: Social Interactions and Sociohistorical Processes. The Case of Chile

Based on empirical research, this article approaches the reasons why, in the case of Chile, interactional inequalities have ended up constituting a privileged lens to read social events as well as to establish judgments about society. The thesis defended is that the relevance of these inequalities in the perception of individuals reveals how the processes of transformation that this society has gone through in the last decades have questioned the principles of the social bond by challenging the social logics that historically kept untouched a hierarchical and vertical conception of social relations. The case of interactions on the streets is taken to argue.

KEYWORDS: inequalities, social interactions, social bond, sociohistorical processes, Chile 


\section{Principio normativo e ideales encarnados en la percepción de las desigualdades}

a percepción de las desigualdades, el tipo de desigualdades que somos capaces de identificar y la falta de legitimidad que le atribuimos dependen de la magnitud y manera específica en que el principio normativo de la igualdad se encarna en la sociedad de la que formamos parte. Que el principio normativo de igualdad se haya incorporado implica tres aspectos: primero, que actúe en efecto como fundamento de las expectativas individuales y colectivas; segundo, que aparezca como un componente de la idea de justicia, y tercero, que funcione como brújula de orientación y evaluación de las sociedades y los individuos respecto de sí mismos y sus trayectos (Therborn, 2006; 2013; Turner, 1986).

Por otro lado, y esto es central, quiere decir que este principio normativo se ha traducido en uno o varios ideales sociales con contenidos específicos. Que el principio de igualdad esté presente en una sociedad no garantiza que, en tanto ideal social, aparezca en otra sociedad con los mismos contenidos o en las mismas esferas que en otras sociedades. Si no fuera así, no podría explicarse que lo que se percibe, evalúa o sanciona como desigualdad no sea lo mismo en una sociedad que en otra.

La percepción de las desigualdades evidencia la manera en que el principio normativo abstracto de la igualdad ha sido sometido a procesos de recepción y traducción en cada sociedad en la que se inscribe como parte del arsenal normativo social. La recepción y traducción son, a su vez, un resultado histórico con componentes de índole social, cultural, económica y política (Wagner, 1997; Rosanvallon, 2011): producto del encuentro entre el principio normativo abstracto de la igualdad y la realidad social e histórica en la que éste se desenvuelve (Araujo, 2013).

Tener en cuenta lo anterior nos pone en guardia respecto de generalizaciones abusivas, de tipo normativo, en la comprensión del problema de las desigualdades. Por ejemplo, nos previene de considerar que podemos "importar" sin más, desde otras realidades, el mapa de las desigualdades, o sea, el conjunto articulado de las 


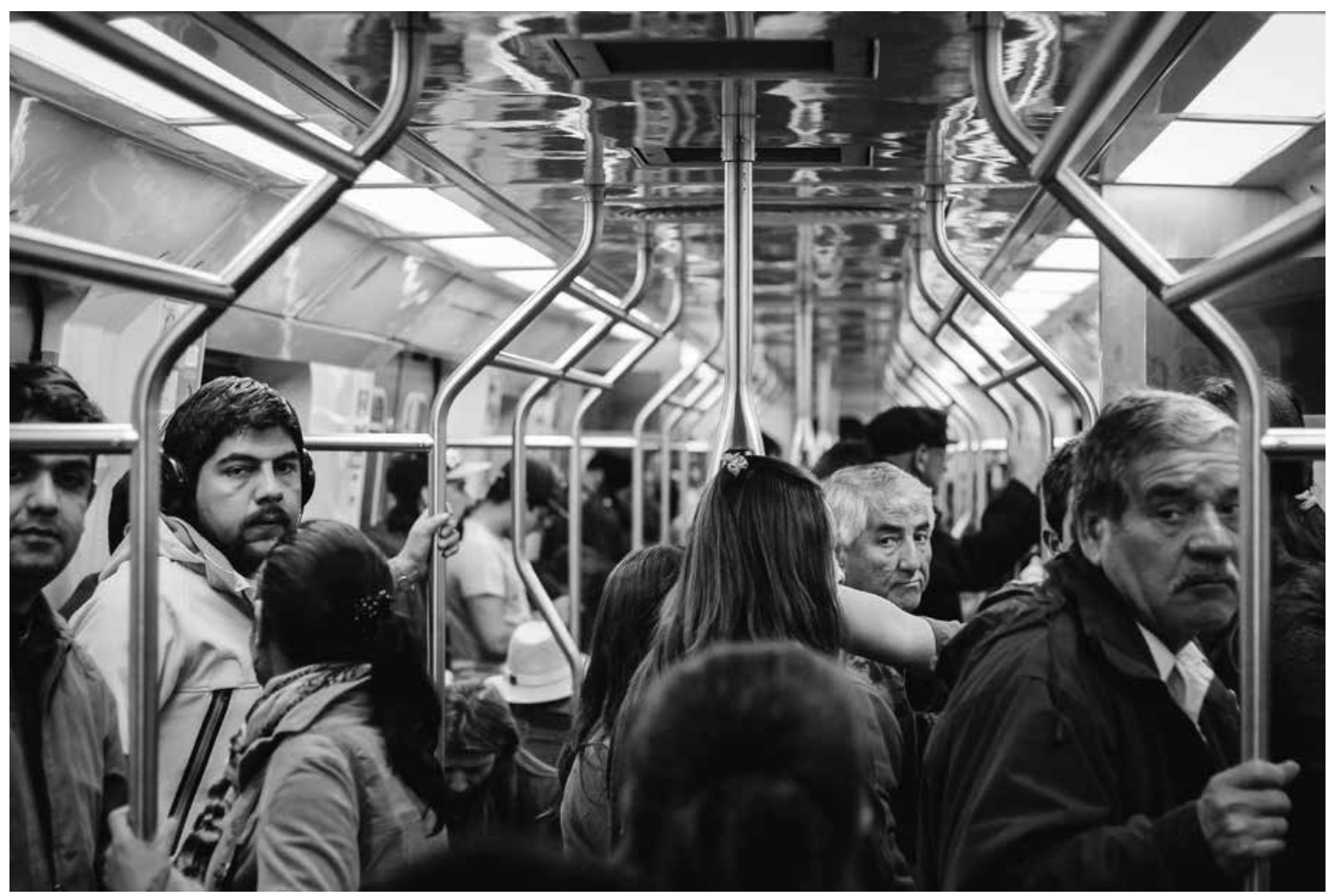

Natalie Lafuente • Caras. Metro de Santiago, junio de 2013.

desigualdades actuantes y sus jerarquías. Al mismo tiempo, en particular para nuestro argumento, esto subraya que las desigualdades percibidas no son un elemento accesorio al estudio de las sociedades, sino una entrada generosa para su comprensión, porque revelan su condición sociohistórica específica (Araujo, 2013). También, por medio de la jerarquía que adquieren unas respecto de otras, señalan las formas que toma el sentimiento de justicia en las sociedades.

En este marco, nos proponemos analizar en detalle la importancia que han adquirido las desigualdades en la interacción, en el mapa de la percepción de las desigualdades en Chile; sus consecuencias y razones. Primero nos detendremos a discutir qué son las desigualdades interaccionales y lo que muestran de la sociedad chilena. Después analizaremos sus expresiones en la vida social a partir del ejemplo de las interacciones en la calle. Por último, propondremos qué razones sociohistóricas explican la significación que han adquirido.

El análisis y el argumento se basan, sobre todo, en los resultados de cuatro investigaciones. ${ }^{1}$ La primera se desarrolló en dos etapas, de 2003 a 2004 y de 2005 a 2007, y se concentró en la manera en que el ideal normativo de derecho, y en consecuencia, de igualdad, participaba o no en la regulación de las relaciones cotidianas entre las personas, y entre éstas y

1

Este artículo se basa en numerosas investigaciones empíricas. Por razones argumentativas y de espacio, no se detallan aquí las evidencias del material empírico. Para una exposición minuciosa de los procedimientos investigativos y sus resultados, véanse Araujo (2009; 2012; 2016a; 2016b); Araujo y Martuccelli (2012). 
las instituciones. Se indagó sobre el tipo de relación con las normas que los individuos establecían y las experiencias sociales que explicaban esa relación. ${ }^{2}$

La segunda se concentró en identificar los desafíos sociales que encaran los sujetos, la jerarquía que se les atribuye y las formas de individuación a las que se les empuja al enfrentarlos. ${ }^{3}$ Aquí sólo se utilizan los resultados relativos a los desafíos que emanan de los procesos de democratización de las relaciones sociales. Esta investigación se llevó a cabo entre 2007 y 2011. La tercera investigación, desarrollada entre 2011 y 2014, se propuso distinguir las formas de ejercicio de la autoridad en el contexto de los procesos de democratización social y expansión del principio normativo de la igualdad en Chile, con acento en el trabajo y la familia. ${ }^{4} \mathrm{El}$ último estudio, de 2016, versa sobre la calle y las desigualdades. El objetivo era aprehender los modos concretos que las personas despliegan a diario para habitar la calle y las experiencias de desigualdad que enfrentan en ellas. ${ }^{5}$

\section{Las desigualdades interaccionales}

Los resultados de nuestras investigaciones mostraron que en Chile las desigualdades interaccionales, un tipo de desigualdades de trato, se habían convertido en las más percibidas y rechazadas por la población (Araujo, 2009; 2013), lo que ha sido confirmado por otros estudios (PNUD, 2015; 2017). Por cierto, la percepción de estas desigualdades no ha anulado las percepciones de desigualdad económica, cultural o jurídica, pero las ha desplazado en importancia (PNUD, 2017). Esta evidencia obliga a subrayar dos puntos. Primero, que es posible observar un cierto desfase entre la centralidad creciente que ha adquirido en el debate público la cuestión de la igualdad socioeconómica en Chile y las maneras en las que los actores sociales perciben las desigualdades (Castillo, 2009; Castillo, Miranda y Carrasco, 2011). En segundo lugar, si la sociedad chilena, como tantas otras en Latinoamérica, sigue estando marcada por una fuerte desigualdad socioeconómica — medida,

2 Se aplicó la técnica de conversación-dramatización en grupo, entre hombres y mujeres de sectores populares y medios, de varios rangos de edad. Se reunió un total de 20 grupos, de cinco a ocho participantes cada uno. Esta investigación fue posible gracias al apoyo de Oxfam Gran Bretaña. Los resultados se discutieron en Araujo (2009). Para una presentación de la técnica utilizada, véase Araujo (2014).

Se llevaron a cabo 96 entrevistas semidirigidas en las ciudades de Santiago, Concepción y Valparaíso. El proyecto fue posible gracias al apoyo de la Comisión Nacional de Investigación Científica y Tecnológica (Conicyt), con el Fondo Nacional de Desarrollo Científico y Tecnológico (Fondecyt) 1085006. Una presentación minuciosa se encuentra en Araujo y Martuccelli (2012).

4 Se realizaron 32 entrevistas semiestructuradas a hombres y mujeres de sectores medios y de menores recursos, y se trabajó con 12 grupos de conversación-dramatización. En ambos casos, un requisito central para ser parte de la muestra fue tener entre 35 y 55 años de edad, dado que la investigación trataba la cuestión de la autoridad de los padres. En las entrevistas y grupos abocados al tema de autoridad y familia, se consideró que tuvieran hijos. La investigación contó con el apoyo de la Conicyt, con el Fondecyt 1110733. Los procedimientos metodológicos y los resultados en extenso pueden consultarse en Araujo (2016a).

5 El trabajo de campo se desarrolló sólo en el Gran Santiago y se organizó a partir de dos modalidades de trabajo etnográfico, la observación participante y la técnica a la que denominamos observación participante de segundo orden. La primera tuvo como fin rastrear las interacciones sociales cotidianas en la calle durante un periodo regular de seis semanas, con tres registros semanales de alrededor de tres horas en cada espacio asignado. Se enfocó en cinco áreas: parques; barrios comerciales y bohemios; transporte público - metro y autobuses-; avenidas, y ejes de confluencia. Se obtuvieron 108 observaciones participantes en total. La segunda modalidad combinó las técnicas de observación participante y entrevista en profundidad para registrar el punto de vista de los actores sobre la calle y sus interacciones. Todas las personas convocadas para este ejercicio desempeñan su actividad laboral en la calle. Un miembro del equipo de investigación las entrevistó cada semana para discutir sus observaciones. Aunque se consideraron ocho actores-informantes, uno abandonó el estudio, por lo que se culminaron siete procesos que involucraron 28 entrevistas. El estudio contó con el auspicio del Programa de las Naciones Unidas para el Desarrollo-Chile y parte de los resultados se publicó en Araujo (2016b). 
por ejemplo, con el índice de Gini-, un aspecto esencial que acompaña este rasgo en la actualidad es que aspira cada vez más a la implementación de un trato horizontal entre las personas.

En efecto, las desigualdades interaccionales son las que más molestan a los chilenos de todos los sectores socioeconómicos y rangos de edad consultados, muy por encima de las económicas (PNUD, 2015: 99). En 2016, 41\% de la población encuestada declaró haber recibido malos tratos en el curso del último año — haber sido "pasado a llevar", ofendido o mirado en menos, discriminado, tratado injustamente o con violencia-, cuestión presente en particular en los sectores populares (PNUD, 2017: 201-203). Lo que los estudios han mostrado, sobre todo, es que las desigualdades en la interacción se han convertido en el barómetro principal con el que se interpretan otras desigualdades, se construyen los juicios sobre la sociedad y se perfila la adhesión al colectivo.

Pero ¿qué son las desigualdades interaccionales? Se refieren a la manera en que somos tratados por otros individuos o instituciones en las interacciones sociales ordinarias y concretas. Importa el trato que recibo del otro: las formas de ejercicio de la jerarquía, los criterios para definir las formas de consideración debidas o la práctica de las normas sociales de cortesía. Todos somos iguales en la medida en que recibimos el mismo trato en las interacciones cotidianas, sin importar la posición social, los signos de distinción que exhibamos o la relación con el poder que ostentemos.

En aras de la claridad conceptual, es necesario explicar por qué no las llamo desigualdades de trato. La respuesta estriba en su especificidad, que es indispensable subrayar. Si bien lo que está en juego, en general, es la cuestión de cómo se es tratado, el peso que toma la dimensión de la interacción es esencial. Esto obliga a diferenciar esta desigualdad percibida de la sostenida en términos de reconocimiento. La dimensión de reconocimiento (Honneth, 1997; Taylor,
2003; Fraser y Honneth, 2006) no está ausente en esta modalidad de las desigualdades de trato vigente en Chile, pero es forzoso señalar que no es el corazón de las inquietudes de los individuos, porque lo que se exige no es el reconocimiento de una identidad ni un reclamo a la intersubjetividad, sino ser "bien" tratados en las interacciones ordinarias. Lo que está en juego en este tipo de desigualdades percibidas está más cerca de la civilidad y la sociabilidad que del orden político y jurídico, más próximo a la idea de “sociedad decente", de Margalit (1999) — para quien una sociedad puede ser injusta o desigual, pero puede intentar no humillar a las personas-, y del "orden de la interacción”, de Goffman (1988), en el que las cuestiones del tacto, la deferencia o el estigma son cruciales para definir a los individuos en la vida social.

En ambos aspectos, de desigualdades basadas en el reconocimiento e interaccionales, se trata de una desigualdad de trato, pero con rasgos distintos. El caso de la sociedad chilena muestra que la forma privilegiada en la que la desigualdad de trato toma cuerpo revela la preeminencia de la inquietud por la interacción propiamente dicha, por encima de la sanción intersubjetiva que se pone en juego en ella. Se enfoca en las lógicas relacionales entre grupos sociales más que en la definición de la cualidad y naturaleza de la identidad individual por medio de los procesos intersubjetivos, como sucede con las desigualdades de trato vinculadas al reconocimiento. Las desigualdades interaccionales están orientadas, en última instancia, hacia las lógicas que gobiernan la interacción social y las maneras en que se traducen en códigos de conducta específicos.

Una consecuencia central de lo anterior es que el principio normativo de la igualdad se ha traducido, para la sociedad chilena, en expectativas de horizontalidad en el trato recibido en las interacciones. La horizontalidad en los intercambios cara a cara se convierte en una exigencia esencial, aunque no cumplida, y ello se especifica en la búsqueda de un nuevo tipo de sociabilidad (Araujo, 2013). 
La importancia de estas desigualdades exhibe, en primer lugar, que las experiencias en las interacciones ordinarias y cotidianas - abordar un autobús, postular a un trabajo, establecer una conversación con un cliente, alternar con los superiores en el ámbito laboral- son espacios privilegiados de encuentro y prueba del vigor y la vigencia de la promesa de igualdad, en su afán de modelar las relaciones sociales. En estas interacciones, los individuos construyen la experiencia de su eficiencia, plausibilidad y modos de cristalización en las lógicas relacionales de la sociedad. La interacción, y con ella ámbitos como los de la sociabilidad y la civilidad, se convierten en esenciales para la construcción de las imágenes que tienen los individuos sobre su sociedad. Son un espacio privilegiado de "verificación" de igualdad, en palabras de Rancière (2004).

La importancia de la percepción de las desigualdades interaccionales muestra también que los chilenos encuentran en estos espacios de "verificación" la permanencia de lógicas relacionales que topan de frente con las expectativas que la promesa de igualdad introduce (Mayol, Azócar y Azócar, 2013). Estas lógicas manifiestan sobre todo la pervivencia de un conjunto de actitudes disímiles, que se inscriben en el registro del rechazo de un trato igualitario entre individuos: las lógicas de mantenimiento de los privilegios, de la superioridad naturalizada, de la confrontación de poderes y el abuso, y del autoritarismo (Araujo, 2009; 2013). Estas experiencias son decisivas para los juicios y representaciones a partir de los cuales se produce o no la adhesión al colectivo. Esto explica, por ejemplo, el papel que ocupa hoy la presunción del abuso como premisa relacional en la desconfianza hacia las elites empresariales y políticas (Márquez, 2015).

En rigor, las desigualdades interaccionales revelan algo esencial acerca del momento que atraviesa la sociedad chilena: la ardua recomposición de los principios que han ordenado no sólo la sociabilidad, sino, en una dimensión más profunda, el lazo social. Se han puesto en jaque las antiguas fórmulas relacionales y ello exige de manera activa, en cada encuentro, una disputa en la definición de los lugares sociales y las atribuciones que legítimamente le corresponden a cada cual. Pero estas experiencias de desigualdad también erosionan el propio principio normativo de la igualdad. La disonancia entre expectativas ideales y lógicas sociales recursivas hace que el principio normativo pierda potencia para ser una orientación efectiva de las formas en que los individuos se conducen. Así se explica, al menos en parte, que en la sociedad chilena convivan hoy expectativas altísimas de un trato horizontal en las interacciones con los otros y las instituciones, con un creciente grado de irritación y desregulación en la sociabilidad ordinaria. Detengámonos en el ámbito de la calle para mostrarlo.

\section{Las desigualdades interaccionales en las calles}

En un estudio reciente, la calle y las interacciones en el espacio público aparecen como un ámbito por excelencia de las desigualdades interaccionales en la sociedad chilena (Araujo, 2016b). La vía pública es cada vez más un verdadero campo de irritaciones. Esto se expresa en la proliferación de conatos de conflicto o microconflictos en situaciones cotidianas como conducir un auto, ser atendido en un restaurante o transitar en un supermercado. Analistas y actores recurren con frecuencia a la metáfora de la "selva urbana" para subrayar la tensión ordinaria en las interacciones entre "fuertes" y "débiles", automovilistas y peatones - entre los que vienen a terciar los ciclistas-; hombres y mujeres, como muestran las movilizaciones contra el acoso y la necesidad imperiosa de hacer horizontal el uso de las calles entre ambos.

Nos acercaremos a dos tipos de desigualdades interaccionales activas en la calle para sostener 
nuestro argumento principal: las que se despliegan en el acto de transitar en la calle y las que se vinculan a la lucha por el espacio y el tiempo.

Las situaciones abiertas de discriminación e incluso prohibición —más o menos legales, pero activas - de acceso a lugares públicos para ciertas personas tienden a desaparecer o debilitarse en términos generales, y cuando se producen, suscitan un rechazo inmediato. En su lugar, sin embargo, se desarrolla un sinnúmero de figuras de microsegregación, de anexión de espacios en función del nivel de ingreso, el género o de criterios generacionales, así como procesos de "privatización" del espacio público, comenzando por el trabajo ambulante. Un rasgo esencial de las calles de Santiago es que el espacio está sometido a un agudo trabajo de territorialización. Los procesos de segregación que ha sufrido la ciudad desde hace algunas décadas se expresan en las representaciones y las prácticas de los actores (Sabatini, Cáceres y Cerda, 2001). Los espacios que deberían considerarse, en principio, comunes tienen "dueño".

El "barrio alto" es de los ricos, la Plaza de Armas es de los extranjeros... Para los que juegan el papel de no propietarios en esta representación imaginaria, estos espacios constituyen el "otro" Santiago. Esto tiene implicaciones concretas en las prácticas, pues definen el curso de los trayectos diarios, las áreas prohibidas, las permitidas o las que se evitan. Esta geografía de representaciones tiene como efecto que el tránsito por la calle sea una experiencia de desasosiego y amenaza potencial, como expresa la reflexión de una de las observadoras participantes en nuestro estudio. Ella proviene de un sector popular y cuando debe ir a observar la zona financiera más dinámica y moderna de la ciudad, por la que no había transitado antes, asienta en su cuaderno de campo:

La sensación que me queda como observadora es que estuve en presencia de otro Chile, otro Santiago, más bien, en el cual tenemos a usuarios que manejan el espacio con mucha autoridad, que hablan de otra forma, incluso en sus tonos de voz se demuestra que son dueños del sector. Esto me llama mucho la atención porque es algo que no había visto. Y puedo concluir, luego de estas jornadas de observación, que precisamente esa apropiación de los espacios públicos, tanto en sectores populares como en barrios más acomodados, se da con dos razones particulares: el poder económico y el poder de intimidar. $^{6}$

El tránsito por la calle se constituye en un surtidor constante de experiencias de desigualdades interaccionales, dos expresiones claras son el miedo a la estigmatización y el miedo a la agresión. ${ }^{7}$ Estos temores manifiestan la convicción de que se enfrentarán malos tratos en las interacciones con los otros, ya sean físicos, como asaltos o golpes, o morales, como humillación y descalificación, e impulsan con frecuencia un trabajo de ocultamiento. Por ejemplo, organizar la presentación de sí orientado por una sobrecivilidad o dar pruebas de rasgos extranjeros domesticados. Para ponerlo en términos de los actores, se trata "de pasar piolita", pasar desapercibido. Claudio, uno de nuestros entrevistados y vendedor ambulante de libros, debe recorrer la ciudad por su ocupación y da testimonio de la dureza de la experiencia de estigmatización: "para mí no hay otro lugar en Santiago más abierto y más cómodo que el persa y la feria. ${ }^{8}$ Me siento a mis anchas como

6

No citamos su nombre por razones de anonimato. Observación participante, barrio El Golf, Las Condes, Santiago, 13 de mayo de 2016.

7 Aun cuando las tasas de homicidio o violencia son mucho más bajas en Santiago que en otras capitales de Latinoamérica (Auyero y Berti, 2013).

8 Persa: mercado de pulgas, por lo general ubicado en sectores populares. Feria: mercado provisional instalado en las calles, en días y horas determinados. Aunque también se colocan en algunas zonas pudientes, se extienden en particular en zonas populares, en las que son importantes para la sociabilidad. 
en ningún otro lugar, porque siento que no tengo que representar ningún personaje" (entrevista con Claudio, Santiago, 28 de abril de 2016). Por otro lado, el temor activa estrategias de evitación, como no transitar ni ocupar espacios públicos en las zonas más pudientes, excepto cuando es forzoso (Fuentes et al., 2017). Esta estrategia es común en otras realidades nacionales (Jounin, 2014) y en los sectores de mayores recursos, en los que se establecen fronteras claras en la circulación ordinaria.

Una suerte de "malignización de la otredad" ha tenido efecto y ha constituido al otro como amenaza y adversario, ha quebrado la noción de un espacio común y le ha dado un marco de confrontación y disputa a las relaciones ordinarias entre los habitantes de la ciudad.

La segunda gran arena urbana de expresión de las desigualdades en las interacciones se centra en los usos del espacio y el tiempo. En términos de los debates públicos, éstos aparecen, por ejemplo, en el anhelo de ciertos grupos sociales de "ganar tiempo" respecto a otros, lo que a veces toma la forma de discusiones sobre el tipo de transporte que debe privilegiarse en el gasto público, sin perder de vista implicaciones ecológicas o de salud - contaminación, longitud de las jornadas, etc.- - La disputa se establece también en las interacciones ordinarias en la ciudad. Un caso ejemplar, pero no único, es el metro de Santiago, porque aparece como una expresión condensada y exponencial de esta realidad.

El metro de Santiago aumentó su capacidad de manera inaudita en la última década. Si en 2006 movilizaba 331 millones de pasajeros al año, en 2015 trasladaba 661 millones (Metro, 2007; 2015). Habitantes de zonas de menores recursos incrementaron el uso de este medio de transporte (Metro, 2014), considerado por muchos la gran expresión de la modernidad del país (Araujo, 2009). También se elevó de manera significativa la afluencia de usuarios del metro en horas pico. El acceso a los beneficios de la modernización y sus consecuencias positivas ha estado acompañado por una experiencia en la que los actores deben desplegar estrategias sofisticadas en sus luchas por el espacio, las cuales suponen interacciones ríspidas hasta el punto de bordear o traspasar los límites de la violencia. Lo esencial: si bien el abarrotamiento en el metro es una experiencia compartida en muchos lugares del mundo, aquí se ha colocado como una de las metáforas privilegiadas del maltrato institucional y la relación con los otros en un espacio de lucha y confrontación.

Ingresar a un vagón, mantenerse o desplazarse en él, o transitar por los corredores de las estaciones en las horas de mayor afluencia de usuarios exponen con frecuencia a situaciones de confrontación de las que se concluye que el más fuerte gobierna las interacciones y define las formas de trato que reciben las personas. Para ocupar estos espacios, es indispensable tener estrategias planificadas, como conocer los lugares en el andén que coinciden con las puertas y ocuparlos de manera ostensible, o recurrir a la fuerza física con toda la energía, es decir, hacer uso de la corporalidad para controlar el espacio, etc. La expresión "ser tratados como animales" es la más común para describir estas escenas en nuestro estudio, en las denuncias en los medios de comunicación o en conversaciones cotidianas. Una de nuestras observadoras expresa esta condición de cuasi objeto; a su juicio, al metro "tú no subes, te suben, en realidad".

El sentimiento de indignidad es el resultado de una situación en la que los usuarios se sienten víctimas y de la que extraen sus críticas más ácidas a la sociedad. Al mismo tiempo, sus actuaciones en estas escenas van en la misma dirección de lo que critican, si les es posible, por cierto. Por ejemplo, se registraron observaciones que relatan que entre la masa de personas que entra o sale de los vagones se escuchan con regularidad invocaciones a no

9 Observación participante, metro de Santiago, abril de 2016. 
empujar, pero muchas veces quienes hacen este reclamo están empujando a las personas frente a ellos.

El metro se convierte en la arena que concentra de manera visible la irritación relacional —insultos o conatos de pelea-. "Estamos súper agobiados, cansados y estresados", dice Marcela, una mujer de 41 años de edad, vendedora de seguros, que debe recorrer tres comunas en un trayecto que va de zonas muy ricas a zonas muy populares:

La gente, para subirse al metro, se empuja, se pega, discuten... Ahí me llamó la atención que una joven le pegó por casualidad con el bolso a una señora y la señora como que explotó, se desahogó, súper agresiva, y las dos comenzaron a contestar. No se dijeron garabatos ni nada, pero sí mucha agresividad. ¿Y el entorno cómo reaccionó? Todos miran, el entorno se altera, pero nadie se mete ni a defender ni a criticar. Estamos todos callados. A mí, personalmente, me dan ganas de meterme, pero lo que a mí me detiene es que pueda terminar mal (entrevista con Marcela, Santiago, 20 de abril de 2016).

Por otro lado, es un espacio en el que se hace evidente que las formas de trato dependerán del uso no legítimo de las diferencias para extraer ventaja: fuerza física, contextura corporal, género, capacidad motora o cognitiva, o edad. Lo anterior redunda, como lo muestran nuestras observaciones en los momentos de mayor tránsito, en que es un sitio cuyo uso es un privilegio para los “sanos”, los jóvenes, los más fuertes, en particular, los hombres.

Por supuesto, esto no puede explicarse, como a veces sucede, como el resultado de un envilecimiento de los individuos por el sistema o por la ausencia de un carácter moral. Las irritaciones se explican por razones estructurales. Establecida de esta manera, la lucha por el espacio es expresión del sentido de competencia impregnado en las personas, una lógica de confrontación de poderes aún presente como estrategia exitosa en la vida social, y sobre todo, de pobladores estresados y presionados por una vida que les exige destinar tiempo excesivo en traslados - en promedio, de 90 a 120 minutos diarios (Bannen, 2011) - ; por el trabajo mismo, de largas jornadas de pluriactividad, a la que se ven obligados por la incertidumbre respecto de su permanencia laboral, o por el "trabajo sin fin" y su demanda desmesurada (Araujo y Martuccelli, 2012).

El metro, sus vagones, corredores y andenes, es un espacio signado por la lucha y la expulsión. Los que están en el lugar de los perdedores — niños, adultos mayores, personas con discapacidad y mujeres- y reciben el maltrato de los más fuertes, que muchas veces pone en riesgo su seguridad personal, deben encontrar nuevas estrategias para sus traslados. Una de mucha importancia es la evitación. Eluden movilizarse en metro para no ser maltratados, o no maltratar a otros, y buscan medios de transporte alternativos, aunque eso implique mayor inversión de tiempo, o si es posible, reestructuran sus horarios. Si antes los pobres se quedaban afuera del metro, hoy son los más débiles. De este modo, los códigos de civilidad presentes hasta hace no mucho han dejado de aplicarse y valorarse en prácticas que, dada su repetición y carácter ordinario, contribuyen a erosionar las maneras convencionales en que se regulaban las asimetrías de poder en la vida social.

A pesar de sus diferencias, estos dos ejemplos tienen algo en común. La vida cotidiana, el día a día, aparece como un objeto cargado de discusión y como un ámbito privilegiado en el cual los individuos aspiran a recibir un trato más horizontal. También revelan que la otra gran tensión que atraviesa a la sociedad chilena hoy es que el anhelo por la igualdad en las interacciones se acompaña por un conjunto de irritaciones variadas en las relaciones con los otros y por un desasosiego en la disputa acerca de lo que cada uno merece recibir en el trato con otros. Esto descubre cuánto aportan las desigualdades interaccionales a las fuerzas de fisión de la sociedad y cómo contribuyen a mantener una representación 


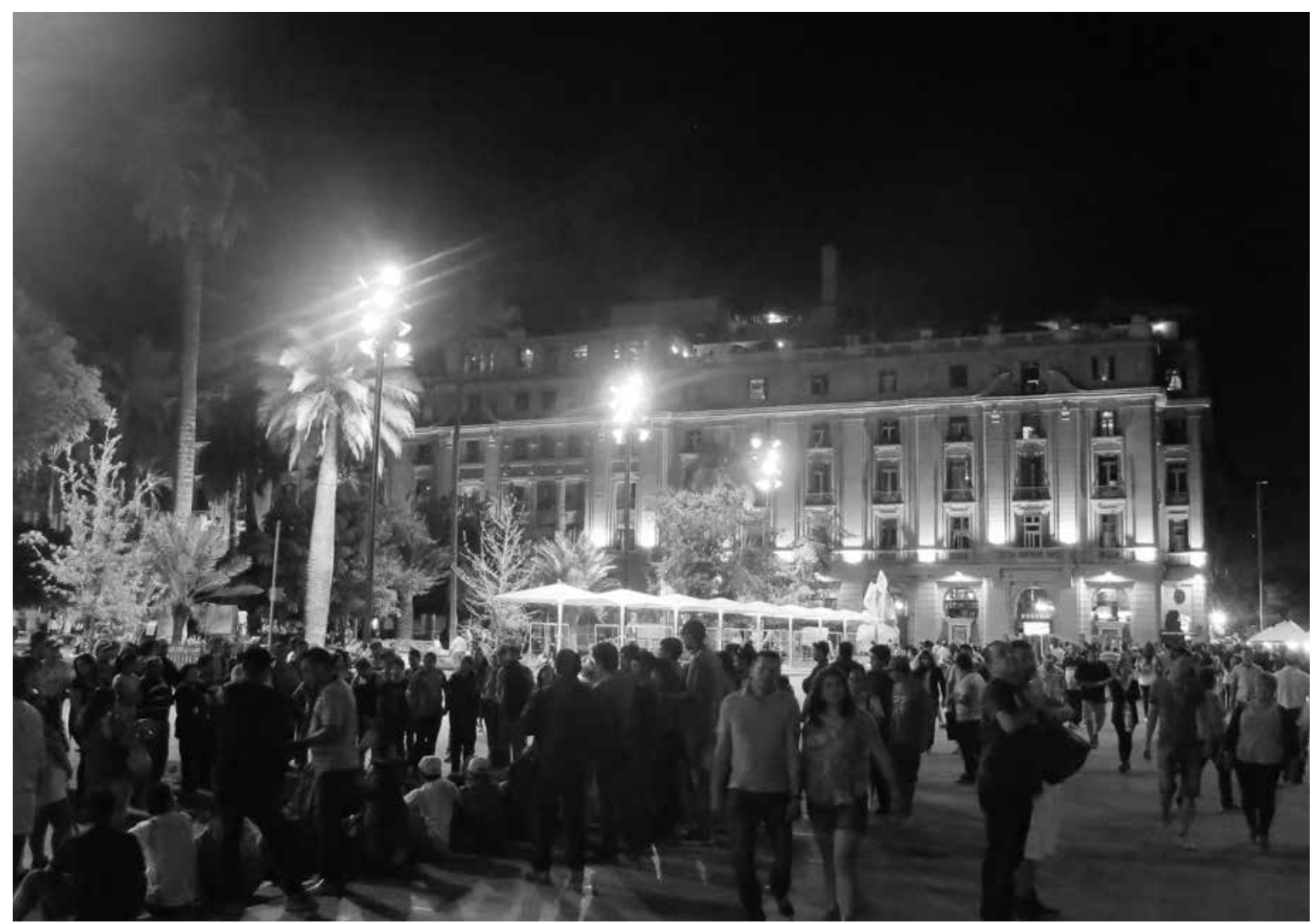

GwennHAel Huesca Reyes Plaza de Armas atestada de turistas y artistas callejeros, Santiago, abril de 2015.

dual y polarizada de ésta, en la que sólo hay lugar para una lectura de confrontación y no colaborativa. Hacen evidente la dificultad de producción de un "común" actuante y convincente para motivar la adhesión al conjunto de la sociedad. Las desigualdades proveen experiencias que terminan por empujar a los individuos a formas de evitación y retracción de las relaciones con los otros, por lo tanto, de la vida colectiva.

En resumen, hemos partido de la importancia que han adquirido las desigualdades interaccionales, respecto a que es un tipo de desigualdad preeminente en la percepción de los individuos, así como para sus juicios, su adhesión al colectivo y la orientación de sus acciones. Argumentamos que esto expone que el principio normativo abstracto de igualdad, en Chile, se ha traducido con fuerza en un tipo de ideal de igualdad cuyo contenido es el trato horizontal entre personas, y entre éstas y las instituciones. Es decir, que el principio normativo de la igualdad se aplica hoy en esta sociedad nacional, y a diferencia de otras sociedades, de manera destacada en el ámbito de las interacciones ordinarias y cotidianas, la sociabilidad y las formas de civilidad. Presentamos cómo aparecen estas desigualdades en las interacciones en la calle y en esa medida mostramos cómo expresan la coyuntura tensa de recomposición del lazo social que atraviesa la sociedad chilena en el momento actual. Ahora hablaremos de la tercera cuestión que propusimos: por qué este tipo de percepción de la desigualdad ha adquirido importancia. 


\section{Procesos sociohistóricos y entramado de la igualdad y la desigualdad}

Una característica que parece congregar el acuerdo de los debates históricos y científico-sociales, no sólo sobre Chile, sino sobre la región latinoamericana, es la preeminencia de una concepción del lazo social en la que la ficción fundadora de lo que articula la relación entre individuos, grupos y dominios sociales ha estado marcada por fórmulas jerárquicas verticales. Esta jerarquía, además, ha sido naturalizada en función de rasgos adscritos, como los apellidos o el color de piel (Quijano, 2000). La ficción de la igualdad como niveladora, al menos retórica, de las asimetrías sociales no estuvo en el centro de la imaginación política y social en buena parte de estas sociedades, como en cambio sucedió en otras, en especial algunas europeas y sobre todo la estadounidense.

Aunque la cuestión de la igualdad ha estado presente en las sociedades latinoamericanas al mismo tiempo que en Estados Unidos y Europa, llega con los arrestos de la Ilustración, vía el despotismo ilustrado, y se entrelaza en los discursos independentistas para quedar en segundo plano (Domingues, 2009; Therborn, 2006). La ficción de la jerarquía vertical fue el ancla de la imaginería principal de ordenamiento de las relaciones sociales y políticas, sostenida y mantenida de maneras diversas, por ejemplo, con la promesa de protección y favores singularizados a la población o las personas, como la figura del hacendado o el clientelismo (Morandé, 1984; Vidal, 1998; Auyero, 2001), o gracias a la idea de la jerarquía como requisito indispensable para el mantenimiento del orden social, político o moral ante el temor del caos y el desborde, como fue el caso de varios prohombres novecentistas de la patria (Svampa, 2006; Guerra, 2001), o en el papel de tutela autoestablecido por instituciones centrales en estas sociedades hasta muy tarde, en el siglo XX, como la Iglesia o el Ejército (Nugent, 2010).
Esta ficción jerárquica y vertical ha sido puesta en evidencia a partir de la endémica brecha entre el mundo imaginado por la institucionalidad — política o jurídica-y lo que en efecto se desarrolló en la vida social, como lo han mostrado Jose Murilo de Carvalho para Brasil (2012) o François-Xavier Guerra para la América hispana (2001). Pero también se ha expuesto al subrayar el carácter tutelar de la relación entre instituciones y pueblo en Latinoamérica, en la que las elites que se arrogaron la capacidad de decisión y acción en nombre del conjunto y la autonomía de los gobernados no se consideraron un elemento decisivo en la ecuación. Éstos y otros rasgos históricos exhiben el predominio de este modelo de jerarquía vertical adoptado por las elites, que caracteriza el lazo social en buena parte de la región, con las especificidades del devenir de cada país.

Así, aunque la igualdad como principio haya estado presente en la historia de la región y haya impulsado transformaciones jurídicas o intervenido en las demandas de ciertos grupos respecto a otros durante el siglo XX, lo cierto es que no consiguió permear de manera consistente el dominio de las relaciones sociales, es decir, las formas de establecimiento del lazo social, ni desestabilizó la ficción fundadora de la jerarquía vertical y naturalizada, en una región en la que, por otro lado, la sociabilidad y las interacciones cara a cara han constituido una esfera significativa para entender la integración social y los juegos dirimentes del poder (O’Donnell, 1984; Da Matta, 2002; Lomnitz, 1992).

Más bien, a lo que hemos asistido durante mucho tiempo ha sido a los límites del principio de igualdad para permear las lógicas relacionales que gobiernan las interacciones entre los miembros de la sociedad. Esto ha sido visible en la disonancia constante entre procesos modernizadores económicos y culturales, y el funcionamiento de las relaciones sociales. Dos ejemplos para el caso chileno: la aún vigente importancia del apellido como 
factor determinante para el acceso a oportunidades sociales (Núñez y Pérez, 2007; PNUD, 2017) y las formas serviles y desreguladas que gobernaron, $y$ en algunos casos aún gobiernan, las relaciones entre empleadores y empleados en el servicio doméstico (Correa, 2016).

Sin embargo, un factor ha comenzado a intervenir en este escenario. En Chile, como en otros países de Latinoamérica, la igualdad como principio e ideal social se ha expandido en una nueva ola en las últimas décadas. Si bien el ideario moderno de libertad igualitaria ha estado presente en el subcontinente como horizonte casi desde el mismo periodo en el que se instaló en Europa y Estados Unidos, los procesos específicos de la región permitirían hablar de un nuevo momento de la igualdad, que ha ganado espacio en el imaginario y avanza en términos de institucionalización (CEPAL, 2010; Sorj y Martuccelli, 2008; Vargas, 2008).

Este cambio, al mismo tiempo político y cultural, ha impulsado una reconfiguración de los contenidos de la democracia y una comprensión particular de los procesos de democratización. En este contexto, la igualdad, en el marco de la expansión del ideal de derecho y la noción de ciudadanía, fue ofrecida en términos normativos a partir de la década de 1990, en el caso chileno en específico, como un valor principal para la sociedad movilizada por múltiples actores: el Estado, el sistema político institucional, la influencia de las agendas de los organismos internacionales, los movimientos sociales y los medios de comunicación, con la difusión masiva de contenidos globales que transmitieron nuevos modelos relacionales y valores, entre otros. Pero la nueva ola de la igualdad trajo consigo, además, objetivos políticos que pusieron en el centro la democratización de las relaciones sociales, establecida respecto a grupos sociales específicos; por ejemplo, entre hombres y mujeres, adultos y niños, o entre culturas. La transformación paulatina de las representaciones sobre la dotación de poder que le cabe a los actores, ya sea en términos políticos o de agencia en la vida social, ha devenido en una imagen fortalecida de sí mismos y ha puesto en tensión la arquitectura tradicional de las asimetrías de poder en las relaciones sociales: hombres-mujeres, niños-adultos, etc. Los efectos de esta concepción de igualdad en el surgimiento de expectativas de horizontalidad en el trato, en las interacciones con los otros y con las instituciones, influyen en el contenido de lo que se espera de manera legítima en los intercambios sociales y presionan hacia la transformación del carácter de los mecanismos de gestión de las asimetrías de poder en las relaciones sociales, entre otros, los principios de civilidad, los códigos de sociabilidad o el ejercicio de la autoridad. En esencia, estas demandas de democratización, que apuntaban en principio a grupos específicos, terminaron por iluminar un aspecto transversal de muchos grupos sociales: el carácter jerárquico y vertical del lazo social mismo.

La fricción entre estas dos corrientes - el mantenimiento de viejas fórmulas relacionales, debido a la larga impermeabilidad de las lógicas relacionales jerárquicas y verticalizantes, y la emergencia de las nuevas expectativas de horizontalidad asociadas a la nueva ola de la igualdad-, ayuda a explicar que las desigualdades en las interacciones sean notorias, y dada su carga histórica, rechazadas. La relevancia de la percepción de las desigualdades interaccionales pone a contraluz que la sociedad chilena hoy atraviesa una rearticulación profunda y activa, tensa y conflictiva, de las fórmulas que gobiernan las interacciones, las legitimidades y las racionalidades sociales.

\section{A modo de conclusión}

El caso de Chile demuestra dos cuestiones teóricas y metodológicas relevantes para el estudio de las desigualdades. Primero, que es indispensable tomar en cuenta los procesos de traducción que sufre el principio abstracto de la igualdad en el encuentro con cada 

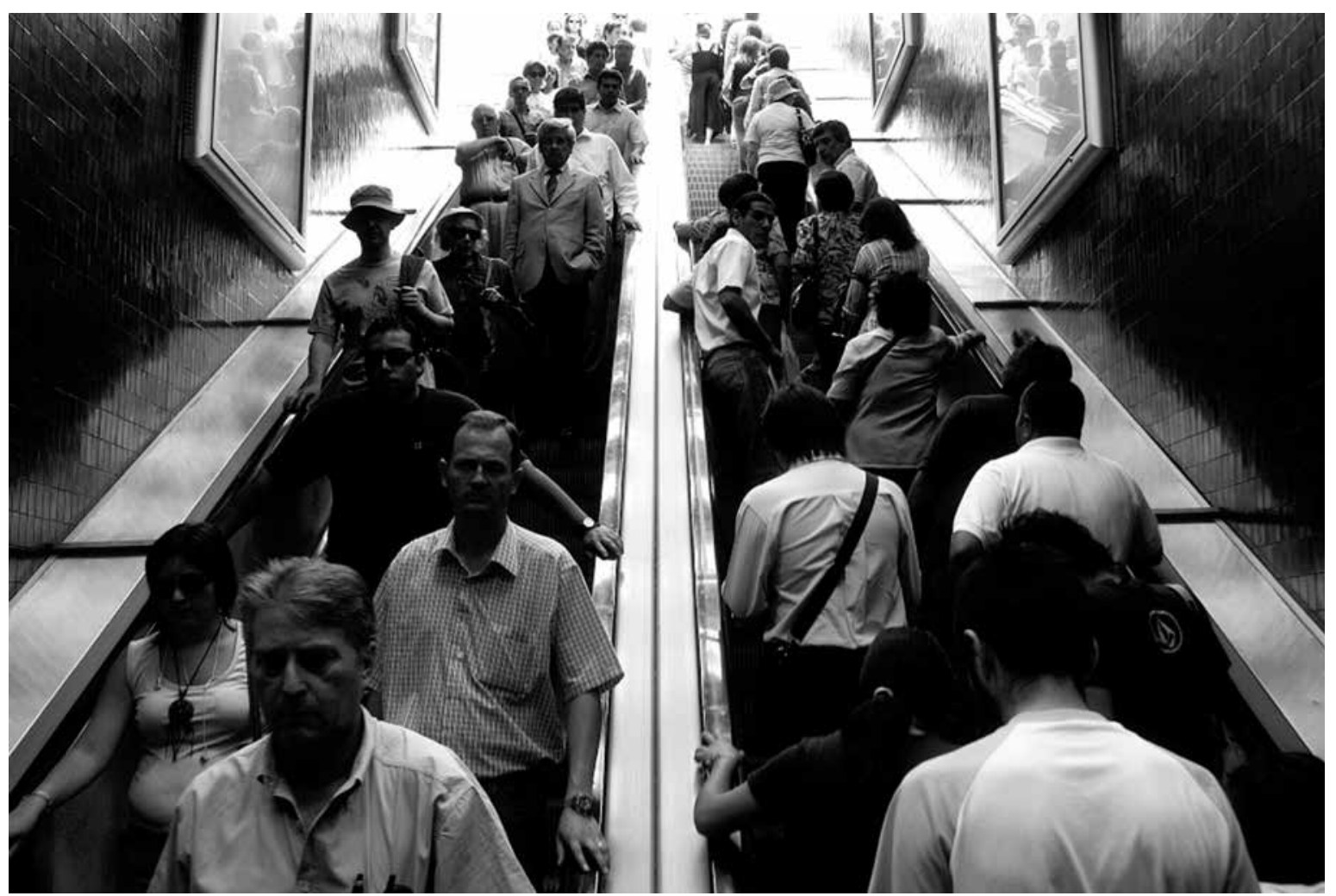

KINOKII - Metro de Santiago, septiembre de 2007.

realidad sociohistórica. Segundo, presenta con transparencia que la manera singular en que se despliega el mapa de las desigualdades percibidas en una sociedad desvela sus desafíos actuales, así como las tareas más urgentes a las que se enfrenta.

Lo discutido también permite atisbar, aunque no haya sido tratado de manera explícita por razones de espacio, las tensiones que se suscitan entre la variedad de registros de las desigualdades y la necesidad de examinarlas en el contexto de sus resonancias múltiples y cruzadas. En efecto, se advierte que esta sensibilidad por las desigualdades interaccionales se produce en una sociedad marcada por desigualdades socioeconómicas importantes. Esto no es menor. En una sociedad como la chilena, se asiste a un divorcio y una tensión mayúscula entre ambos registros de la igualdad. El mantenimiento y la reproducción de desigualdades socioeconómicas profundas, a pesar de la movilidad social y los cambios introducidos en la educación, coincide con el incremento y el reforzamiento de demandas de igualdad interaccional. Esto plantea la pregunta de hasta qué punto es posible hacer horizontales las relaciones entre actores desiguales en sus asimetrías socioeconómicas principales. Al mismo tiempo, obliga a cuestionar en qué medida los individuos intentan obtener en el trato interaccional lo que sienten que no podrán conseguir en términos de mayor igualdad socioeconómica.

Por último, se echa luz sobre las exigencias a las que nos enfrentamos como científicos sociales en Latinoamérica. Pocas cosas muestran con tanta claridad la importancia creciente de las desigualdades interaccionales como el contraste observable 
entre su presencia en el discurso de los actores y la producción académica. Por ejemplo, si el tema de las desigualdades interaccionales ha estado presente en las sociedades europeas al menos desde las reflexiones en torno a la civilidad y la cortesía, sobre la necesidad de restablecer "formas" y "maneras" después de que la Revolución francesa cuestionara los privilegios estatutarios (Raynaud, 2013), y aún más en Estados Unidos desde las observaciones pioneras de Tocqueville (1961) hasta los trabajos decisivos de Goffman (1973), nada semejante se observa en nuestra región. Por supuesto, hubo manuales de buenas costumbres e imperativos higienistas en el ámbito público, pero el tema estuvo muy lejos de tener la importancia política que tuvo en otras sociedades. Aquí es donde el cambio de expectativas de los individuos termina por iluminar la falta de atención a una esfera esencial para nuestra vida social. Como se muestra con el análisis de las desigualdades interaccionales, las ciencias sociales requieren hacerse cargo hoy del reconocimiento de la centralidad de las interacciones y la sociabilidad ordinaria como componentes primeros y primarios del lazo social para el caso latinoamericano. D

\section{Bibliografía}

Araujo, Kathya, 2009, Habitar lo social, LOM, Santiago.

- 2012, "La relación con las normas en América Latina y el ordinario trabajo moral del sujeto”, en Stefanie Kron, Sérgio Costa y Marianne Braig (eds.), Democracia y reconfiguraciones contemporáneas del derecho en América Latina, Iberoamericana/Vervuert, Madrid, pp. 19-41.

__ 2013, "La igualdad en el lazo social: procesos sociohistóricos y nuevas percepciones de la desigualdad en la sociedad chilena", en Dados. Revista de Ciencias Sociais, vol. 56, núm. 1, pp. 109-132.

__ 2014, "Artesanía e incertidumbre: el análisis de los datos cualitativos y el oficio de investigar", en Manuel Canales (coord.), Escucha de la escucha, LOM, Santiago, pp. 43-73.

_- 2016a, El miedo a los subordinados, LOM, Santiago.

__, 2016b, "La calle y las desigualdades interaccionales", documento de trabajo, Programa de Naciones Unidas para el Desarrollo, Santiago.

Araujo, Kathya y Danilo Martuccelli, 2012, Desafíos comunes, 2 tt., LOM, Santiago.

Auyero, Javier, 2001, La politica de los pobres, Manantial, Buenos Aires.

Auyero, Javier y María Fernanda Berti, 2013, La violencia en los márgenes, Katz, Buenos Aires.

Bannen, Pedro, 2011, "Santiago de Chile puesto a prueba (1973-1977)-(2008-2010): miradas sobre una metrópolis tensada entre reestructuración y crisis", en Carlos de Mattos, Wiley Ludeña y Luis Fuentes (eds.), Lima-Santiago. Reestructuración y cambio metropolitano, Pontificia Universidad Católica de Chile/Pontificia Universidad Católica del Perú, Lima, pp. 41-63.

Carvalho, Jose Murilo de, 2012, Os bestializados, Companhia das Letras, São Paulo.

Castillo, Juan Carlos, 2009, “¿Cuál es la brecha salarial justa? Opinión y legitimación de la desigualdad económica en Chile”, en Estudios Públicos, núm. 113, pp. 237-266.

Castillo, Juan Carlos, Daniel Miranda y Diego Carrasco, 2011, "La percepción desigual de la desigualdad”, informe técnico 1101, Pontificia Universidad Católica de Chile-Centro de Medición MIDE, Santiago.

Comisión Económica para América Latina y el Caribe (CEPAL), 2010, La hora de la igualdad. Brechas por cerrar, caminos por abrir, Comisión Económica para América Latina y el Caribe, Santiago de Chile.

Correa, Verónica, 2016, Entre sumisión y emancipación: mujeres latinoamericanas frente a la prueba inmigratoria en Santiago de Chile, tesis de doctorado, École des Hautes Études en Sciences Sociales/Universidad de Chile, París.

Domingues, José Maurício, 2009, La modernidad contemporánea en América Latina, Siglo XXI Editores, Buenos Aires. 
Empresa de Transporte de Pasajeros Metro (Metro), 2007, Memoria anual Metro S. A. '07, Empresa de Transporte de Pasajeros Metro, Santiago. Disponible en línea: <https://www.metrosantiago.cl/files/documentos/anuario.pdf>, consultado el 25 de julio de 2016.

__ 2014, Reporte de sostenibilidad 2014, Empresa de Transporte de Pasajeros Metro, Santiago. Disponible en línea: <http://www.metro. $\mathrm{cl} /$ minisitio/memoria2014/pdf/reportesostenibilidad2014.pdf>.

__ 2015, Memoria anual 2015, Empresa de Transporte de Pasajeros Metro, Santiago. Disponible en línea: <https://www.metrosantiago.cl/ files/documentos/memoria2015/memoria-anual-2015.pdf>

Fraser, Nancy y Axel Honneth, 2006, ¿'Redistribución o reconocimiento?, Morata, Madrid.

Fuentes, Luis, Oscar Mac-Clure, Cristóbal Moya y Camilo Olivos, 2017, "Santiago de Chile: ¿ciudad de ciudades? Desigualdades sociales en zonas de mercado laboral local”, en Revista de la CEPAL, núm. 121, pp. 93-108.

Goffman, Erving, 1973, La mise en scène de la vie quotidienne, t. 1, Minuit, París.

, 1988, “L'ordre de l'interaction”, en Erving Goffman, Les moments et leurs hommes, Seuil/Minuit, París, pp. 186-230.

Guerra, François-Xavier, 2001, Modernidad e independencias, Mapfre/Fondo de Cultura Económica, México.

Honneth, Axel, 1997, La lucha por el reconocimiento, Crítica, Barcelona.

Jounin, Nicolas, 2014, Voyage de classes, des étudiants de Seine-Saint-Denis enquêtent dans les beaux quartiers, La Découverte, París.

Lomnitz, Claudio, 1992, “Usage politique de l'ambigüité: le cas mexicain”, en L'Homme, año 32, núm. 121, pp. 91-102.

Margalit, Avishai, 1999, La sociedad decente, Paidós, Barcelona.

Márquez, Rodrigo, 2015, “La distancia entre la ciudadanía y las elites”, en Estudios Públicos, núm. 140, pp. 83-106. Disponible en línea: <https:// www.cepchile.cl/cep/site/artic/20160810/asocfile/20160810125219/rev140_rmarquez.pdf>.

Matta, Roberto da, 2002, Carnavales, malandros y héroes, Fondo de Cultura Económica, México.

Mayol, Alberto, Carla Azócar y Carlos Azócar, 2013, El Chile profundo. Modelos culturales de la desigualdad y sus resistencias, Liberalia, Santiago.

Morandé, Pedro, 1984, Cultura y modernización en América Latina, Pontificia Universidad Católica de Chile, Santiago.

Nugent, Guillermo, 2010, El orden tutelar, Consejo Latinoamericano de Ciencias Sociales, Lima.

Núñez, Javier y Graciela Pérez, 2007, “'Dime cómo te llamas y te diré quién eres': la ascendencia como mecanismo de diferenciación social”, Universidad de Chile-Departamento de Economía (Serie Documentos de Trabajo 269), Santiago.

O’Donnell, Guillermo, 1984, ¿Y a mi qué me importa? Notas sobre sociabilidad y política en Argentina y Brasil, Centro de Estudios de Estado y Sociedad, Buenos Aires.

Programa de las Naciones Unidas para el Desarrollo (PNUD), 2015, Desarrollo humano en Chile. Los tiempos de la politización 2015, Programa de las Naciones Unidas para el Desarrollo, Santiago.

—_, 2017, Desiguales. Orígenes, cambios y desafíos de la brecha social en Chile, Programa de las Naciones Unidas para el Desarrollo, Santiago

Quijano, Aníbal, 2000, "Coloniality of Power, Eurocentrism and Latin America”, en Nepantla: Views from South, vol. 1, núm. 3, pp. $533-574$.

Rancière, Jacques, 2004, Aux bords du politique, Gallimard, París.

Raynaud, Philippe, 2013, La politesse des Lumières, Gallimard, París.

Rosanvallon, Pierre, 2011, La société des égaux, Seuil, París.

Sabatini, Francisco, Gonzalo Cáceres y Jorge Cerda, 2001, "Segregación residencial en las principales ciudades chilenas: tendencias de las últimas tres décadas y posibles cursos de acción”, en EURE. Revista Latinoaméricana de Estudios Urbano Regionales, vol. 27, núm. 82 pp. 5-24.

Sorj, Bernardo y Danilo Martuccelli, 2008, El desafío latinoamericano, Siglo XXI Editores, Buenos Aires.

Svampa, Maristella, 2006, El dilema argentino: civilización o barbarie, Taurus, Buenos Aires.

Taylor, Charles, 2003, El multiculturalismo y la politica del reconocimiento, Fondo de Cultura Económica, México.

Therborn, Göran, 2006, “Meaning, Mechanisms, Patterns, and Forces of Inequalities. An Introduction”, en Göran Therborn (ed.), Inequalities of the World. New Theoretical Frameworks. Multiple Empirical Approaches, Verso, Londres.

,2013, The Killing Fields of Inequality, Polity Press, Cambridge.

Tocqueville, Alexis de, 1961, De la démocratie en Amérique, Gallimard, París.

Turner, Brian, 1986, Equality, Ellis Horwood/Tavistock, Chichester y Londres. 
Vargas, Virginia, 2008, Feminismos en América Latina. Su aporte a la política y a la democracia, Universidad Nacional Mayor de San Marcos/ Centro de la Mujer Peruana Flora Tristán/Programa Democracia y Transformación Global, Lima.

Vidal, Dominique, 1998, La politique au quartier, Maison des sciences de l'homme, París.

Wagner, Peter, 1997, Sociología de la modernidad, Herder, Barcelona.

\section{Entrevistas}

Claudio, Santiago, 28 de abril de 2016.

Marcela, Santiago, 20 de abril de 2016. 